\title{
(쇼
}

\section{Kounis Syndrome in a Young Patient After Bee Sting: Case Report}

\author{
Arı Sokmasına Bağlı Genç Hastada Kounis Sendromu: Olgu Sunumu
}

\author{
Murat Ayan', Hasan Kadı², Mehmet Esen', Kerem Özbek² \\ 'Department of Emergency Medicine, Faculty of Medicine, Gaziosmanpaşa University, Tokat, Turkey \\ 2Department of Cardiology, Faculty of Medicine, Gaziosmanpaşa University, Tokat, Turkey
}

\section{ABSTRACT}

Hypersensitivity reactions due to insect bites cause different clinical situations ranging from simple urticaria to myocardial infarction. Acute coronary syndrome caused by insect bites is called Kounis syndrome. Myocardial infarction (MI) is one of the most common causes of mortality and morbidity in the world. Following a bee sting, a 43-year-old male patient was admitted to the emergency room with severe chest pain. Upon physical examination of the patient, blood pressure was $85 / 50 \mathrm{~mm} / \mathrm{Hg}$, heart rate was 60 beats/minute and respiratory rate was 12/ minute. The ECG of the patient showed a significant ST elevation in anterior derivations. Treatment was started with intravenous antihistamines and steroids. After fifteen minutes, decreased ST segment elevation in anterior derivations were detected on the ECG of patient. Coronary angiography revealed $80 \%$ stenosis in the left anterior descending artery (LAD). As a result, we suggest that emergency room physicians should consider the use of antihistamines and steroids in with to bee stings in Kounis syndrome patients.

Keywords: Acute coronary syndrome, insect bites, allergic reaction Received: 13.12.2011 Accepted: 11.01.2012

Available Online Date: 20.05.2013

\section{ÖZET}

Böcek sokmaları hipersensivite reaksiyonu ile basit bir ürtikerden miyokard infarktüsüne kadar gidebilen değişik klinik durumlara sebeb olmaktadır. Böcek sokmalarının neden olduğu akut koroner sendromlara Kounis sendromu denmektedir. Miyokard infarktüsü (Mi) tüm dünyadaki mortalite ve morbiditenin en yaygın sebeplerinden biridir. Kırk üç yaşında erkek hasta arı sokmasını takiben şiddetli göğüs ağrısı yakınması ile acil servise başvurdu. Fizik muayenesinde kan basıncı 85/50 mm/Hg, nabız 60/dk idi. Hastanın çekilen EKG'sinde anterior derivasyonlarda (V1-V6) belirgin ST yükselmesi mevcuttu. Antihistaminik ve steroid tedavisinden 15 dakika sonra çekilen EKG'de anterior derivasyonlardaki ST segment elevasyonlarının gerilediği tespit edildi. Akut anterior MI tanısı ile kateter laboratuarına alınan hastada sol ön inen arter (LAD) proksimalinde \%80 lezyon tespit edildi. Sonuç olarak arı sokması sonrasında acil servise başvuran hastalarda Kounis sendromunun da göz önünde bulundurularak antihistaminik ve steroid grubu ilaçların kullanılması düşünülmelidir.

Anahtar Kelimeler: Akut koroner sendrom, böcek ısırı̆ı̆ı, allerjik reaksiyon

Geliş Tarihi: 13.12.2011 Kabul Tarihi: 11.01.2012

Çevrimiçi Yayın Tarihi: 20.05.2013

\section{Giriş}

Böcek sokmaları çeşitli immünolojik yolaklar vasıtasıyla basit bir hipersensivite reaksiyonu olan ürtikerden şiddetli anjioödeme kadar değişen tabloya sebep olmaktadır (1). Dahası alerjik reaksiyona ikincil olarak gelişen koroner vazospazm ve akut miyokard infarktüsüne (Mi) kadar gidebilen bir klinik tabloya yol açabilmektedir. Bu klinik duruma "Kounis sendromu" denmektedir (2). Kounis sendromu; ilaçlar, çeşitli çevresel maruziyetler, arı sokmaları, zehirlenmeler, lateks alerjisine kadar birçok durum sebep olmaktadır (3). Mi, tüm dünyadaki mortalite ve morbiditenin en yaygın sebeplerinden biridir. Mi, koroner arterin trombüs nedeniyle tam olarak tıkanması sonucu oluşur ve her yıl 7 milyondan daha fazla sayıda insanı etkilediği tahmin edilmektedir. MI gelişmiş ülkelerde daha sık görülmekle beraber gelişmekte olan ülkelerde sıklığı giderek artmaktadır (4). Damar duvarındaki erozyona hassas plakların sebep olduğu epikardial koroner arter tıkanıklığı fetal ölümcül olayların çoğundan sorumlu tutulmaktadır $(5,6)$. Mi bulantı, kusma, terleme gibi klasik semptomların yanında bazen farklı klinik şekilde de kendini gösterebilir. Bu nedenle hastaların \%4-6'sı doğru teşhis konulamaması sonucu acil servislerden yanlışlıkla taburcu edilebilmektedir (7). 


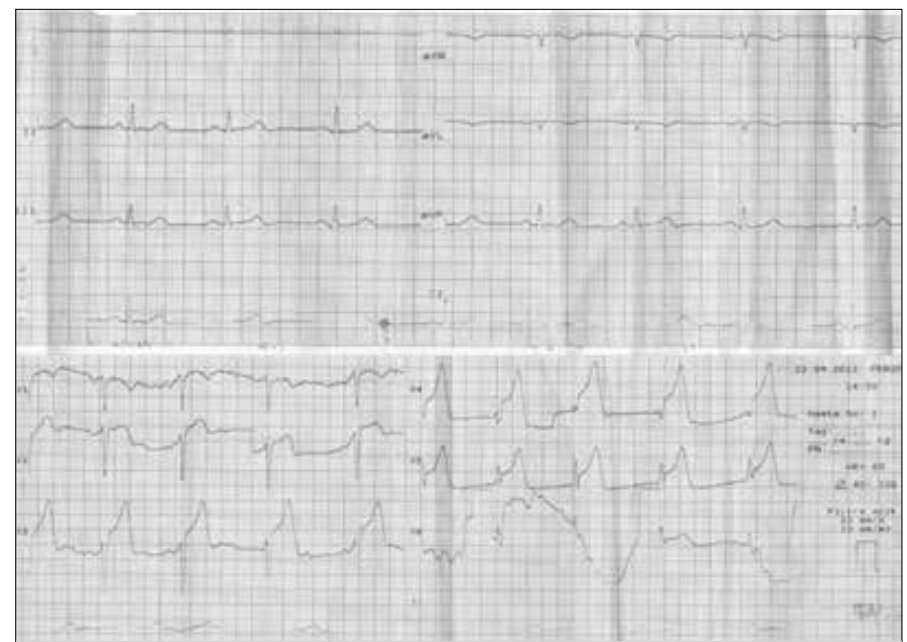

Şekil 1. Başvuru EKG

\section{Olgu Sunumu}

Kırk üç yaşında erkek hasta arı sokmasını takiben başlayan göğüs ön tarafından başlayıp sırta doğru yayılan şiddetli göğüs ağrısı yakınması ile acil servise başvurdu. Fizik muayenesinde kan basıncı 85/50 mm/ Hg, nabız 60/dk, kalp ritmikti, ek ses veya üfürüm yoktu. Hastanın çekilen EKG'sinde sinüs ritmi, kalp hızı 58 atım/dk ve anterior derivasyonlarda (V1-V6) belirgin ST yükselmesi mevcuttu (Şekil 1). Hastanın tıbbi özgeçmişinde diabetes mellitus, hipertansiyon, dislipidemi veya daha önce bilinen koroner arter hastalığı hikayesi yoktu. Hasta acil servise geldiğinde 325 mg asetilsalisilik asit oral olarak çiğnetildi. Intravenöz olarak feniraminmaleat 45,5 mg, 2 mg morphine, 1 mg/ kg'dan prednisolone ve nazal oksijen tedavisi başlandı. Antihistaminik ve steroid tedavisinden 15 dakika sonra çekilen EKG tetkikinde

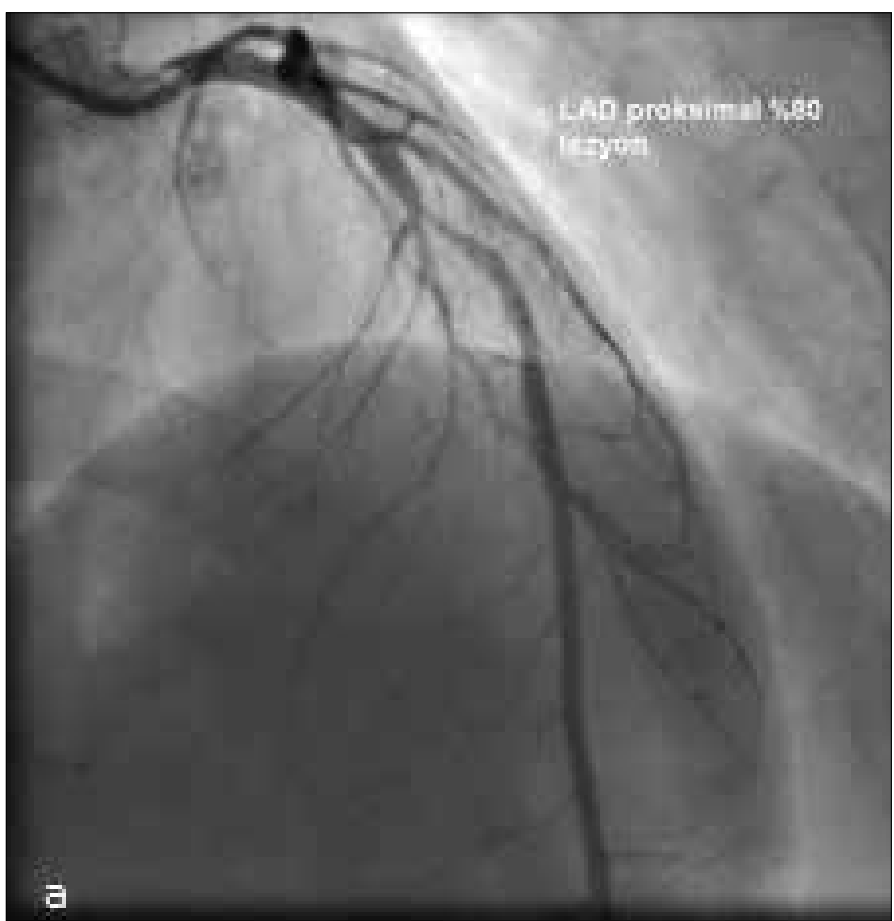

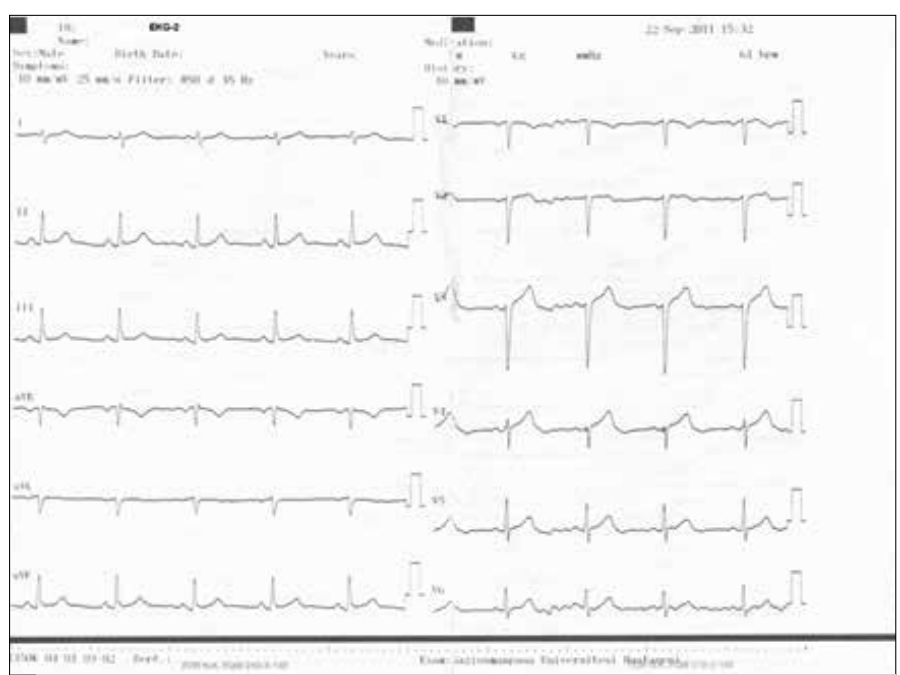

\section{Şekil 2. Tedavi sonrası EKG}

(Şekil 2) anterior derivasyonlardaki ST segment elevasyonlarının gerilediği tespit edildi. Hastanın kardiyak belirteçleri Troponin; 2,64 ng/ mL, kütle CK-MB; 120,6 ng/mL idi. Akut anterior MI tanısı ile kateter laboratuvarına alınan hastaya koroner anjiyografi ve LAD lezyonuna primer perkütan koroner girişim yapıldı. Koroner anjiografisinde sol ön inen arter (LAD) proksimalinde \%80 lezyon tespit edildi. Lezyona direkt stent yerleştirildi (Resim 1). İşlem sonrası yapılan ekokardiyografide sol ventrikül ejeksiyon fraksiyonu \%45 ve anterior duvar mid ve apikal bölgesinde hafif hipokinezi saptandı. Takiplerinde kardiyak enzimleri geriledi, dinamik EKG değişikliği olmadı. Göğüs ağrısı tekrarlamayan hasta medikal tedavisi düzenlenerek taburcu edildi.

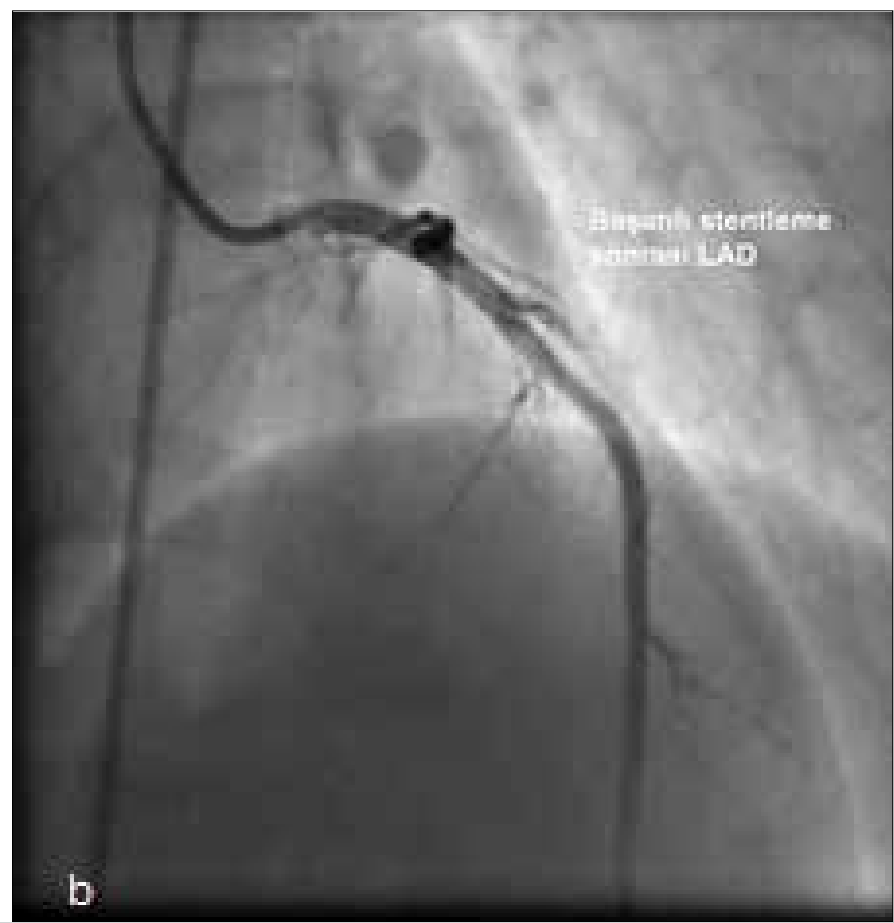

Resim 1. LAD \%80 lezyon (a) ve direk metal kaplı stent yerleştirilmesi sonrasında tama yakın açılma sağlandı 


\section{Tartışma}

Kounis sendromu ilk olarak 1991 yılında Kounis tarafından tanımlanmıştır (8). Bu sendromda histamin, nötral proteaz, araşidonik asit ürünleri, platelet aktive edici faktör (PAF) ve mast hücre degranülasyonunun dahil olduğu inflamatuar mediatörlerin kanda artması koroner arter spasmına, aterom plağının rüptürüne veya erozyonuna neden olduğu gösterilmiştir. Bu gibi alerjik reaksiyonların akut koroner sendromların ortaya çıkmasına sebep olduğunu belirtmişlerdir (8-10). Günümüzde Kounis sendromunun fizyopatolojik nedenine bağlı olarak, iki tipi tanımlanmıştır. Tip 1; Koroner arterlerin normal olup, akut alerjik olayların tetiklediği birtakım zincirleme reaksiyonlar sonucu koroner vazospazm, anstabil anjina ve miyokard infarktüsüne kadar giden ciddi klinik durumları içerir. Tip 2 ise önceden var olan aterom plaklarının akut alerjik epizotlarla plağın erozyonu veya rüptürüyle oluşan durum olarak tanımlanmıştır (2). Literatürde alerjik reaksiyonlar ile akut koroner sendromu ilişkisi ile ilgili vakalar nadir olarak karşımıza çıkmaktadır (2). Nikolaidis ve ark. (11) daha önceden koroner arter hastalığı öyküsü olmayan, akut alerjik reaksiyon veya astım atağı şikayeti başvuran sekiz hastanın koroner anjiografilerinin incelendiği bir çalışmada hastaların büyük çoğunluğunda koroner damarlarda \%70'den daha fazla darlık olduğunu tespit etmişlerdir. Bununla ilişkili olarak araştırmacılar atopik bünyeye sahip kişilerde aşırı artmış mast hücre degranülasyonunun plak rüptürüne yol açabileceği hipotezini ileri sürmüşlerdir. Literatürde daha öncede bizim vakamıza benzer anterior miyokard infarktüsü ile başvuran birkaç olgu bildirilmiştir $(10,11)$. Arı sokması sonrasında acil servise başvuran vakalarda başvuru sırasında veya başvurudan saatler sonrasında bile reaksiyon şiddetinden bağımsız olarak koroner vazospasm veya plak rüptürü sonucu akut koroner sendrom geliştiği belirtilmiştir (12). Bizim vakamızda tıpkı Tip 2 Kounis sendromunda olduğu gibi arı venomunun içeriğinde bulunan epinefrin, dopamin, lökotrienler ve tromboksanın dahil olduğu bir takım mediatörler vasıtasıyla hastada LAD'de var olan lezyonlu damarda plak rüptürü ve vazospazma yol açarak tam tıkanıklığa yol açarak anterior MI tablosunun ortaya çıkmasına sebep olduğunu düşünmekteyiz (13).

\section{Sonuç}

Arı sokması sonrasında acil servise başvuran hastalarda Kounis sendromunun da göz önünde bulundurularak antihistaminik ve steroid grubu ilaçların kullanılması düşünülmelidir.

\section{Conflict of Interest}

No conflict of interest was declared by the authors.

Peer-review: Externally peer-reviewed.

\section{Author Contributions}

Concept - M.A., H.K.; Design - M.E.; Supervision - M.E., K.Ö.; Funding M.A.; Materials - M.A., H.K.; Data Collection and/or Processing - M.A.,
H.K., M.E., K.Ö.; Analysis and/or Interpretation - M.A., H.K.; Literature Review - M.A., H.K.; Writer - M.A.; Critical Review - M.E., K.Ö.

\section{Çıkar Çatışması}

Yazarlar herhangi bir çıkar çatışması bildirmemişlerdir.

Hakem değerlendirmesi: Dış bağımsız.

\section{Yazar Katkıları}

Fikir - M.A., H.K.; Tasarım - M.E.; Denetleme - M.E., K.Ö.; Kaynaklar - M.A.; Malzemeler - M.A., H.K.; Veri toplanması ve/veya işlemesi - M.A., H.K., M.E., K.Ö.; Analiz ve/veya yorum - M.A., H.K.; Literatür taraması - M.A., H.K.; Yazıyı yazan - M.A.; Eleştirel İnceleme - M.E., K.Ö.

\section{Kaynaklar}

1. Freeman TM. Clinical practice. Hypersensitivity to hymenoptera stings. $\mathrm{N}$ Engl J Med 2004; 351: 1978-84. [CrossRef]

2. Kounis NG. Kounis syndrome (allergic angina and allergic myocardial infarction): a natural paradigm? Int J Cardiol 2006; 110: 7-14. [CrossRef]

3. Kogias JS, Sideris SK, Anifadis SK. Kounis syndrome associated with hypersensitivity to hymenoptera stings. Int J Cardiol 2007; 114: 252-5. [CrossRef]

4. White HD, Chew DP. Acute myocardial infarction. Lancet 2008; 372: 570-84. [CrossRef]

5. Falk E, Shah PK, Fuster V. Coronary plaque disruption. Circulation 1995; 92: 657-71. [CrossRef]

6. Libby P. Current concepts of the pathogenesis of the acute coronary syndromes. Circulation 2001; 104: 365-72. [CrossRef]

7. Collinson PO, Premachandram S, Hashemi K. Prospective audit of incidence of prognostically important myocardial damage in patients discharged from emergency department. BMJ 2000; 320: 1702-5. [CrossRef]

8. Kounis NG, Zavras GM. Histamine-induced coronary artery spasm: the concept of allergic angina. Br J Clin Pract 1991; 45: 121-8.

9. Mytas DZ, Stougiannos PN, Zairis MN, Tsiaousis GZ, Foussas SG, Hahalis $\mathrm{GN}$, et al. Acute anterior myocardial infarction after multiple bee stings. A case of Kounis syndrome. Int J Cardiol 2009; 134: 129-31. [CrossRef]

10. Schmidt R, Bultmann A, Ungerer M, Joghetaei N, Bulbul O, Thieme S, et al. Extracellular matrix metalloproteinase inducer regulates matrix metalloproteinase activity in cardiovascular cells: implications in acute myocardial infarction. Circulation 2006; 113: 834-41. [CrossRef]

11. Nikolaidis LA, Kounis NG, Gradman AH. Allergic angina and allergic myocardial infarction: a new twist on an old syndrome. Can J Cardiol 2002; 18 508-11.

12. Erbilen E, Gulcan E, Albayrak S, Ozveren O. Acute myocardial infarction due to a bee sting manifested with ST wave elevation after hospital admission. South Med J 2008; 101: 448. [CrossRef]

13. Massing JL, Bentz MH, Schlesser P, Dumitru C, Louis JP. [Myocardial infarction following a bee sting. Apropos of a case and review of the literature]. Ann Cardiol Angeiol 1997; 46: 311-5. 